\title{
Correction to: Hemophagocytic lymphohistiocytosis in activated PI3K delta syndrome, an illustrative case report
}

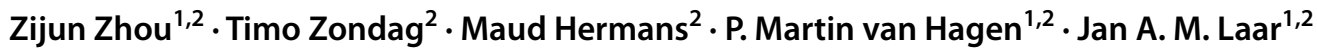 \\ Published online: 9 February 2022 \\ ○) Springer Science+Business Media, LLC, part of Springer Nature 2022
}

\section{Correction to: Journal of Clinical Immunology (2021) 41:1656-1659 https://doi.org/10.1007/s10875-021-01080-w}

The original version of this article contains an error in the nucleotide change of the patients mutation. The correct nucleotide change is a heterozygous c.3074A $>$ G mutation in the PIK3CD gene (NM_005026.3). This was incorrectly stated in the case description, Fig. 2 and in the title of Fig. 2. Although the nucleotide change was stated incorrectly, the subsequent amino acid change (p.Glu1025Gly) was correct throughout the text. Therefore, our further findings and conclusions are unaffected.

Publisher's Note Springer Nature remains neutral with regard to jurisdictional claims in published maps and institutional affiliations.

First authors, these authors have contributed equally to the manuscript.

The original article can be found online at https://doi.org/10.1007/ s10875-021-01080-w.

Jan A. M. Laar

j.vanlaar@erasmumc.nl

1 Department of Immunology, Laboratory Medical Immunology, Erasmus University Medical Centre, Rotterdam, the Netherlands

2 Department of Internal Medicine, Section Clinical Immunology, Erasmus University Medical Center, Rotterdam, The Netherlands 